higher education research as policymakers or advisers struggle to understand the situation and seek alternative policy approaches. Policymakers may turn to research as a legitimizing tool within the political process, but policy can also be made in situations where there is no research base. Several participants noted that in some respects higher education researchers need policymakers and practitioners more than the latter need higher education researchers.

Another layer of complexity is added when one considers the various ways of defining or understanding higher education research. For a number of participants from the United States, Canada, Australia, and the United Kingdom, higher education was viewed as an interdisciplinary field of study, a broadly defined area of academic research. In these countries there are scholars who define themselves as specialists in the study of higher education, as well as research centers, peer-reviewed journals, and-especially in the United States-graduate programs and other attributes of a scholarly field of study. Some participants from places with a less-developed infrastructure for research tended to discuss higher education as an area of emphasis associated with the more traditional disciplines. In other words, an economic study of a particular university might be viewed as a contribution to economics based on the application of economic principles to the university, rather than as a contribution to higher education as a distinct field of scholarly inquiry.

There were also discussions about the relationship between higher education as an interdisciplinary field of study and the parent disciplines. Several people suggested that higher education is a largely derivative field, borrowing theoretical frameworks and methodologies from parent disciplines but seldom contributing new perspectives to the scholarly debates within those disciplines. Others pointed to the benefits of being interdisciplinary: the pulling together of ideas and perspectives from a variety of disciplines. How we view higher education can also be influenced by the way in which centers and academic programs are configured within our own universities-academics attached to a faculty of education may have quite a different view from those working in a research center attached to a department of public policy, for example.

Despite differences of opinion, participants agreed that more research on higher education is needed. This was articulated by policymakers who often find that there is no indigenous research on even the most essential questions related to higher education, and who, in the absence of local expertise, have been forced to employ international consultants to provide guidance on local issues. Some scholars from less-developed nations reported sometimes being unable to obtain data on even the most basic research questions and having to rely on information published by international agencies to understand local issues. Even in countries with a more established tradition of higher edu- cation research, important policy and practice issues may receive relatively little attention by researchers. In some countries, higher education is a major area of government expenditure and yet there is little support for research on higher education. Participants concluded that UNESCO and the new United Nations University should be asked to play an active role in articulating the importance of higher education research, facilitating the broader development of expertise in higher education, and developing additional forums for the dissemination of research findings. These and other issues raised during the Tokyo roundtable will be communicated to participants at the UNESCO World Conference on Higher Education later this year in Paris.

\section{Tertiary Distance Learning in Africa}

\section{William Saint}

William Saint is coordinator for the Working Group on Higher Education. Address: The World Bank, 1818 H Street, N.W., Washington, D.C. 20433.

$\mathrm{T}$ ertiary distance learning initiatives were the focus of a review convened last year by the Working Group on Higher Education - an arm of the Association for the Development of Education in Africa (ADEA). Held October 20-22, 1997 at the Université Gaston Berger in SaintLouis, Senegal, discussants reviewed the results of two surveys and 10 case studies that had been commissioned by ADEA to determine the efficacy of current distance learning initiatives in sub-Saharan Africa. (These materials are currently being incorporated into a report that will be available in French and English by April 1998.) Analysis of the survey responses indicates that only three countries-Madagascar, Mauritius, and South Africa-have national distance learning policies in place. A number of other countries, in spite of their long experience with distance learning, currently function without similar policies.

Distance learning programs pursue different goals in different countries. Their most common use involves the training and upgrading of teachers in primary and secondary schools. As a means of delivering postsecondary education, they are far less common. Only two countries, the Congo and South Africa, are experienced in providing correspondence courses in the subregion. But this is slowly changing: Madagascar increasingly employs distance learning in the education of first-year university students; Tan- 
zania, Zimbabwe, and Botswana possess recently established distance learning institutions for tertiary studies; the University of Namibia has reportedly decided to become a dualmode institution by combining distance instruction with campus-based courses; and, linked via satellite with French universities, the University of Abidjan has experimented with distance training in math, information science, and the sciences.

Distance learning programs pursue different goals in different countries.

According to the two surveys, correspondence courses have been the most common method of instruction. Such courses-in some cases little more than the mailing of lecture summaries to students-are gradually being abandoned due to their limited effectiveness. In their place, specially prepared distance learning materials associated with a teacher/facilitator who guides periodic group discussions are growing in use. ${ }^{1}$

The use of telematics for tertiary distance learning is limited but expanding. The "Telesun" program in Cameroon provides Internet-based courses in the sciences. The FORST program links Benin and three other countries with McGill University in Canada. The RESAFAD program in Djibouti provides teacher training from French universities. Two very recent "virtual university" initiatives are described below.

Capacities for the development of distance learning materials and programs are quite limited. Specialized training centers for distance learning exist only in Madagascar, Mauritius, and South Africa. However, Togo and Congo are now setting up university-based distance training programs. CÙte d'Ivoire is also conducting a feasibility study in this area.

The use of telematics for tertiary distance learning is limited but expanding.

Among the programs reviewed, success is clearly linked to several factors. Primary among them are the existence of an articulated national policy on distance learning, support for distance learning by the nation's political leadership, and the recognition of distance learning degrees by the civil service in their assessments of employee applicant qualifications. Other factors include the availability of professionally trained distance learning staff to manage the program, the complementary use of several different kinds of media, and the existence of follow-up and support programs for learners to reinforce teaching.

Not surprisingly, the main difficulties encountered by programs tend to be the absence of the very factors that promote success. These include the absence of an accepted national policy, of high-level political support for distance learning, of formal recognition of distance learning degrees within the country, of adequately trained distance learning staff, of sufficient management autonomy in terms of control over program staff and budget, and of adequate domestic infrastructure (e.g., roads, postal system, telecommunications).

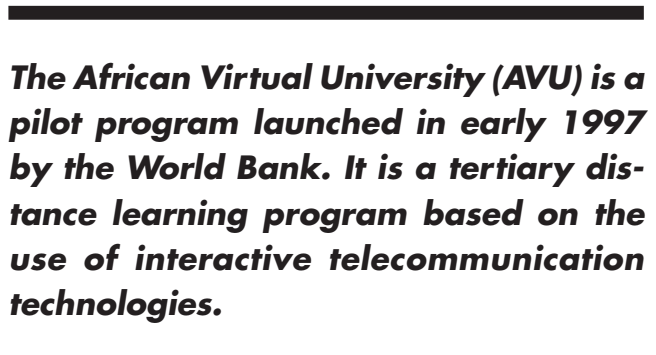

The future prospects for distance learning in Africa are broadly optimistic. Interest in the field is expanding rapidly as governments and institutions struggle to expand enrollments under severe budget constraints. Conditions appear particularly conducive in Burkina Faso, Côte d'Ivoire, Kenya, Tanzania, and Zimbabwe. Concurrently, political leaders are becoming more aware of the potential uses of distance learning to boost the quality of teaching in basic education, to offer learning opportunities to disadvantaged adults, and to extend education services into the more remote areas of their countries. As telecommunications infrastructure steadily improves, experience with the Internet is growing. In the specific area of tertiary distance learning, the World Bank's African Virtual University and AUPELF's Francophone Virtual University are pilot projects that bear watching.

\section{African Virtual University}

The African Virtual University (AVU) is a pilot program launched in early 1997 by the World Bank. It is a tertiary distance learning program based on the use of interactive telecommunication technologies. Its goals are to raise the quality of teaching programs in key disciplinary areas to a competitive international level, to provide stable learning programs that are not vulnerable to the strikes and campus closures that characterized many African universities in the 
1990s, and to expand access to higher education in costeffective ways.

The AVU program will be implemented in three phases. During an initial phase (mid-1997 to mid-1998), teaching technologies and the organization of the delivery system will be tested using short courses in math, physics, and nursing. This pilot project is now underway in 12 anglophone universities. ${ }^{2}$ In early 1998 they will be joined by a dozen francophone universities. By mid-1998, three Portuguese-speaking universities will come on line. During a second phase (mid-1998 to mid-1999), actual degree courses will be offered. In a final phase, the proven methodology will be franchised to interested public and private institutions in Africa.

The present AVU pilot courses were reviewed by curriculum experts from Africa, and the courses are being continually modified based on feedback from students and teaching staff. The courses are a mix of live broadcast lectures and prerecorded tapes. A talk-back system functions via e-mail for student questions and discussion. Textbooks are also used. Examinations are given and marked by local university lecturers.

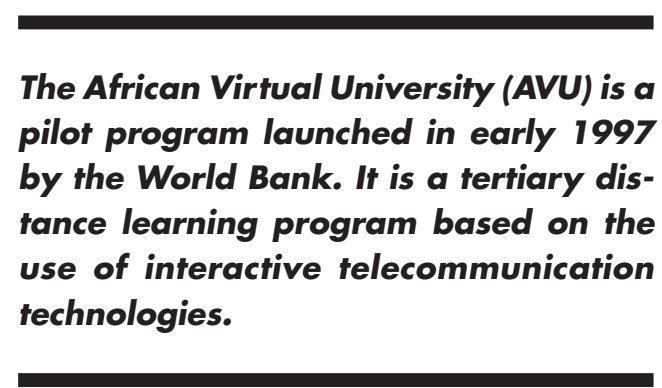

On the basis of the first four months of experience, a number of positive achievements have been realized. For instance, students taking an AVU summer calculus course performed better than similar students taking a traditional university course. Early efforts to expand course offerings into business-related areas have also encountered a favorable response. To date, cost-sharing requirements have encountered no resistance. Most importantly, student enthusiasm is high.

\section{Francophone Virtual University}

In 1987 the Association des Universites Partiellement ou Entierement de Langue Francaise established a "university" composed of French-speaking higher education networks. Known by its French acronym, UREF, it was intended to function as a university without walls, by promoting institutional collaboration in research, teaching, and information exchange. UREF subsequently developed numerous videodiscs, compact discs, databases, and knowl- edge resources in support of this purpose. Telematic centers-popularly referred to as REFER (the electronic network of French-speaking countries) - were created in 25 different countries to provide Internet access and also email communication. Building upon the REFER structure, the Francophone Virtual University seeks to utilize modern information technologies serving the teaching, research, and information access needs of francophone Africa. During 1998 experimental distance learning courses will be offered in agronomy, business management, chemistry, law, mathematics, medicine, and physics. On this basis, a formal program of tertiary studies will be set up by the year 2000.

\section{It appears certain that distance learning will become a major component of Afri- can tertiary education in the next decade.}

\section{Conclusions}

It appears certain that distance learning will become a major component of African tertiary education in the next decade. Nevertheless the development of distance learning in southern Africa is likely to be quite different from experiences with open universities and similar undertakings in the northern reaches of the continent.

In the future, it is possible that tertiary distance learning may exist in the absence of a national university in many African countries. Or it may be highly decentralized, or based on multicountry cooperative efforts. Incipient cooperation already exists between Mauritius and Madagascar, and the potential for joint efforts between South Africa and its neighbors, and between Côte d'Ivoire and Burkina Faso is also evident. Whatever its future, and despite not yet being well defined, distance learning clearly will certainly play an important role in Africa.

\section{Notes}

1. UNESCO and the Agence de Coopération Culturelle et Technique ("Agence de la Francophonie") are reportedly preparing an inventory of all existing distance learning course materials available in the French language.

2. Addis Ababa University, Kenyatta University, National University of Science and Technology (Zimbabwe); the universities at Cape Coast, Dar es Salaam, Legon, and Kumasi in Ghana; Makerere University, Martyrs Catholic University, and Uganda Polytechnic in Uganda, the Open University of Tanzania, and the University of Zimbabwe. 